\title{
A importância da Assistência Estudantil em tempos de pandemia: um relato de experiências do Núcleo de Desenvolvimento Educacional da Universidade Federal do Pampa - Campus Uruguaiana
}

The importance of student assistance in times of pandemic: An account of experiences of the Nucleus for Educational Development of the Federal University of Pampa - UruguaianaCampus La importancia de la atención al estudiante en tiempos de pandemia: relato de experiencias del Centro de Desarrollo Educativo de la Universidad Federal de la Pampa - Campus Uruguaiana

Elomar Christina Vieira Castilho Barilli

ORCID: https://orcid.org/0000-0001-6558-0200 Fundação Oswaldo Cruz, Brasil E-mail: elobrll@gmail.com

Lisiane Guterres Pedroso

ORCID: https://orcid.org/0000-0002-6930-4411 Universidade Federal do Rio Grande do Sul, Brasil

E-mail: lisiguterres@gmail.com

Naiane Soares Druzian

ORCID: https://orcid.org/0000-0001-5642-066X Universidade Federal do Pampa, Brasil

E-mail: nayanesd@hotmail.com

Suelen Martini Azambuja

ORCID: https://orcid.org/0000-0002-0232-6456 Secretaria de Educação do Estado de Santa Catarina, Brasil

E-mail: suelenmartini@unochapeco.edu.br

Márcio Magera Conceição

ORCID: https://orcid.org/0000-0001-6477-4580 Universidade Paulista, Brasil E-mail: magera@uol.com.br

Ricardo Santos de Almeida ORCID: https://orcid.org/0000-0003-1266-2557

Universidade Federal de Santa Maria, Brasil

E-mail: ricardosantosal@gmail.com

Eloy Pereira Lemos Junior

ORCID: https://orcid.org/0000-0001-7968-7279

Universidade de Itaúna, Brasil

E-mail: eloy.junior@uol.com.br

Amanda Zanesco Crivellaro

ORCID: https://orcid.org/0000-0002-8664-4127

Universidade Federal do Pampa, Brasil

E-mail: amandazanescocrivelaro@gmail.com

Lilia de Oliveira Silva

ORCID: https://orcid.org/0000-0003-2431-8454

Rede Estadual de Ensino de Mato Grosso, Brasil

E-mail: lilia_pedagogabg@ @otmail.com

Carlos Magno Araujo Castelo Branco

ORCID: https://orcid.org/0000-0001-7058-2083

Universidade Estadual do Maranhão, Brasil

E-mail: carlosbranco@professor.uema.br

Luciane Porto Frazão de Sousa

ORCID: https://orcid.org/0000-0002-5605-7327 


\author{
Patrícia Pato dos Santos \\ ORCID: https://orcid.org/0000-0002-8054-976X \\ Universidade Anhanguera Uniderp, Brasil \\ E-mail: ppscgms@gmail.com \\ Érica Paula Borri Bezerra \\ ORCID: https://orcid.org/0000-0003-3735-6839 \\ Result Soluções Educacional, Brasil \\ E-mail: profericaborri@gmail.com \\ Joana Maristela Moreira Moleda \\ ORCID: https://orcid.org/0000-0003-1538-7749 \\ Rede de Ensino Municipal e Estadual de Uruguaiana, Brasil \\ E-mail: moleda.jo@gmail.com \\ Vanderlan Feitosa de Macêdo \\ ORCID: https://orcid.org/0000-0002-1957-7323 \\ Universidade Federal do Vale do São Francisco, Brasil \\ E-mail: vanderlanmacedo@ufpi.edu.br \\ Laís Souza da Costa \\ ORCID: https://orcid.org/0000-0003-4620-4677 \\ Universidade Federal do Pará, Brasil \\ E-mail: lays.costta@gmail.com \\ João Kiala Vioka Panzo \\ ORCID: https://orcid.org/0000-0002-9341-8697 \\ Universidade Federal do ABC, Brasil \\ E-mail: joaopanzo261@gmail.com \\ Ivanildo dos Santos \\ ORCID: https://orcid.org/0000-0002-0827-380X \\ Instituto Federal de Educação Ciências e Tecnologia do Amapá, Brasil \\ E-mail: ivanildodossantos021066@gmail.com
}

\begin{abstract}
Resumo
O artigo enfoca as políticas de Assistência estudantil realizadas pelo Núcleo de Desenvolvimento Educacional NuDE da Universidade Federal do Pampa, Unipampa, Campus Uruguaiana, expressas em ações de apoio financeiro para os bolsistas de Assistência estudantil, com o objetivo de problematizar a relação entre vulnerabilidade socioeconômica com os desafios trazidos pela pandemia, especificamente o período de isolamento social e o Ensino Remoto Emergencial (ERE). A discussão aqui colocada se empenha em evidenciar a forte ligação entre os estudantes em situação de vulnerabilidade social e sua permanência, compreensão que sustentou o levantamento dos níveis de satisfação destes sujeitos. O estudo se apoia nos pressupostos teóricos da gestão escolar participativa, inserindo as políticas na ótica democrática. Metodologicamente, a pesquisa, de caráter quanti-qualitativo, de natureza exploratória, buscou entender o papel das políticas a partir do olhar dos assistidos, adotando, como marco teórico de análise, a antropologia do desenvolvimento, Devido a extensão da investigação, este artigo enfoca a primeira fase referindo-se à satisfação geral e desafios enfrentados pela população estudada, a partir três categorias principais: saúde mental, equilíbrio financeiro e desafios para adaptação ao ERE traduzidas em cinco questões colocadas no instrumento de coleta de dados. A condição de inclusão foi a renda familiar não exceder a um salário mínimo e meio por pessoa. Os resultados mostraram que as ações de Assistência Estudantil (auxílios financeiros para complementação da alimentação, aluguéis e infraestrutura de conexão) têm contribuído com os estudantes assistidos. Os auxílios ainda foram ampliados abarcando demandas emergenciais (Auxílio à Inclusão Digital) para melhorar acesso ao ERE, promovendo a permanência dos estudantes, mesmo em meio à crise da COVID-19.
\end{abstract}

Palavras-chave: Pandemia; Assistência estudantil; Políticas; Vulnerabilidade socioeconômica.

\begin{abstract}
The article focuses on the Student Assistance policies carried out by the Educational Development Nucleus - NuDE of the Federal University of Pampa, Unipampa, Campus Uruguaiana, expressed in financial support actions for Student Assistance scholarship recipients, with the aim of problematizing the relationship between socioeconomic vulnerability with the challenges brought by the pandemic, specifically the period of social isolation and Emergency Remote Learning (ERE). The discussion presented here strives to highlight the strong connection between students in a situation of social vulnerability and their permanence, an understanding that supported the survey of these subjects' levels of satisfaction. The study is based on the theoretical assumptions of participatory school management, inserting policies in a democratic perspective. Methodologically, the research, of a quantitative-qualitative, exploratory nature, sought to understand the role of policies from the perspective of those assisted, adopting, as a theoretical framework for analysis, the anthropology of development. Due to the extent of the investigation, this article focuses the first phase referring to the general satisfaction and challenges faced by the studied population, based on three main categories: mental health, financial balance and challenges to adapt to the ERE translated into five questions posed in the data collection instrument. The inclusion condition was the family income not exceed a minimum wage and a half per person. The results showed that Student Assistance actions (financial aid to supplement food, rent and connection infrastructure)
\end{abstract}


have contributed to assisted students. The aid was also expanded to cover emergency demands (Aid to Digital Inclusion) to improve access to the ERE, promoting the permanence of students, even in the midst of the COVID-19 crisis.

Keywords: Pandemic; Student assistance; Policies; Socioeconomic vulnerability.

\section{Resumen}

El artículo se centra en las políticas de Asistencia al Estudiante que lleva a cabo el Núcleo de Desarrollo Educativo NuDE de la Universidad Federal de Pampa, Unipampa, Campus Uruguaiana, expresadas en acciones de apoyo financiero a los becarios de Asistencia al Estudiante, con el objetivo de problematizar la relación entre vulnerabilidad socioeconómica con los desafíos traídos por la pandemia, específicamente el período de aislamiento social y Aprendizaje Remoto de Emergencia (ERE). La discusión aquí presentada busca resaltar la fuerte conexión entre los estudiantes en situación de vulnerabilidad social y su permanencia, entendimiento que apoyó la encuesta sobre los niveles de satisfacción de estos sujetos. El estudio se basa en los supuestos teóricos de la gestión escolar participativa, insertando las políticas en una perspectiva democrática. Metodológicamente, la investigación, de carácter cuantitativocualitativo, exploratorio, buscó comprender el papel de las políticas desde la perspectiva de los asistidos, adoptando, como marco teórico de análisis, la antropología del desarrollo. Por la amplitud de la investigación, Este artículo centra la primera fase en referencia a la satisfacción general y los desafíos que enfrenta la población estudiada, con base en tres grandes categorías: salud mental, equilibrio financiero y desafíos para adaptarse a los ERE traducidos en cinco preguntas planteadas en el instrumento de recolección de datos. La condición de inclusión fue que el ingreso familiar no exceder un salario mínimo y medio por persona. Los resultados mostraron que las acciones de Asistencia al Estudiante (ayudas económicas para complementar la infraestructura de alimentación, alquiler y conexión) han contribuido a la asistencia a los estudiantes. La ayuda también se amplió para cubrir demandas de emergencia (Ayudas a la Inclusión Digital) para mejorar el acceso a los ERE, promoviendo la permanencia de los estudiantes, incluso en medio de la crisis del COVID-19.

Palabras clave: Pandemia; Asistencia estudiantil; Políticas; Vulnerabilidad socioeconómica.

\section{Introdução}

A crise social, econômica, política, ambiental e ética ocasionada pela pandemia trazida pelo novo Coronavírus (SARSCOV-2), trouxe consequências que afetaram diretamente as vidas das populações mundiais. No ensino de nível superior, tais consequências atingiram toda a comunidade de aprendizagem e, particularmente os discentes, privados de dar continuidade às suas pesquisas ao mesmo tempo em que vivenciavam as carências de cunho humano-econômico como insegurança alimentar, saúde mental e garantia de trabalho e renda, preponderantes para a continuidade de seu processo de aprendizagem.

A necessidade do isolamento social fez com que as instituições formadoras com prática presencial já consolidada, buscassem se adequar às metodologias, técnicas e recursos do denominado Ensino Remoto Emergencial (ERE) o que, mesmo no período de transição, gerou preocupação e ansiedade, pois nem todos (estudantes, docentes e família) tinham tido a oportunidade de desenvolver habilidades, tampouco acesso aos recursos e infraestrutura próprias desta nova forma de aprender

no ensino digital. Necessidades básicas para o aprendizado digital iluminaram fatores, tais como: carência de aparelhos eletrônicos, conexões ineficientes à internet, agitação familiar no ambiente residencial (Appenzeller et al., 2020).

A Universidade Federal do Pampa (Unipampa) realiza, como política Institucional, a Assistência Estudantil a fim de garantir os direitos à dignidade e à cidadania, atributos essenciais à no ensino superior humanizado.

A discussão promovida ao longo deste trabalho enfatiza o contexto da Unipampa no que tange aos assuntos estudantis, comunitários, sociais e econômicos (Pina \& Rosa, 2018), motivada por responder à seguinte questão: As ações de Assistência Estudantil promovidas pela Unipampa foram importantes para favorecer a permanência dos estudantes incluídos nos parâmetros de vulnerabilidade socioeconômica considerando o contexto pandêmico?

A resposta para esta pergunta não se resume simplesmente a resultados estatísticos, uma vez que fatores intimamente ligados à subjetividade humana das populações vitimizadas pelas desigualdades sociais ainda tão presentes nas sociedades brasileiras, conformam diferentes realidades vividas pelo público-alvo da Assistência Estudantil. Neste sentido, o objetivo deste trabalho é problematizar a relação entre os desafios trazidos pela pandemia e a política se Assistência Estudantil, explicitando a importância das políticas de assistenciais em prol da permanência dos discentes mais vulneráveis socioeconomicamente. 


\section{Contextualizando a Realidade Vivenciada pelos Discentes do Campus Uruguaiana}

A Constituição Federal cidadã de 1988, em seu artigo 205, assegura que [...] "A educação, direito de todos e dever do Estado e da família, será promovida e incentivada com a colaboração da sociedade, visando ao pleno desenvolvimento da pessoa, seu preparo para o exercício da cidadania e sua qualificação para o trabalho".

Fazendo jus a tais diretrizes constitucionais, a política de Assistência Estudantil se destaca tanto para fomentar o acesso e permanência acadêmica dos estudantes, quanto acesso ao mundo do trabalho.

Ainda com bases no Plano Nacional de Assistência Estudantil, a Unipampa vem ao longo dos anos implementando ações para mitigar os problemas sociais enfrentados por estudantes das mais diversas partes do país. Cada um traz em si uma história de vida, um contexto e a herança social vivida por si e por sua família. O reflexo disso já é evidenciado no seu ingresso na universidade, pois devido a situação de desigualdade social de nosso país, a realidade de muitos deles é de vulnerabilidade socioeconômica, algo que impacta diretamente na sua permanência e conclusão do curso. Muitos vêm de outras cidades e estados do país trazendo consigo apenas a mochila, cheia de sonhos e esperanças, desvalidos e sem apoio financeiro familiar. Segundo o Plano Nacional de Assistência Estudantil:

Para a elaboração de projetos na área de assistência estudantil, é essencial reconhecer que, no Brasil, grande parte da população vivencia diversas formas de segregação e condições de miséria, que variam de intensidade. Há um enorme contingente de jovens que não tem oportunidade de educação, de cultura, de lazer e condições mínimas de moradia e de saúde. Nesse sentido, urge o engajamento das universidades públicas, não apenas no debate, mas na concretizando ações que possibilitem o acesso e sobretudo a permanência no meio universitário em condições dignas e de forma equânime. (Brasil, 2010).

Na contramão do incremento dos níveis de exclusão da maioria dos jovens brasileiros, mesmo aqueles que conseguem chegar ao ensino público de nível superior, a política de Assistência Estudantil vem buscando contribuir para inclusão de jovens estudantes por meio do suporte socioeconômico e acadêmico.

A oportunidade de ser amparado pela política de Assistência Estudantil, é uma motivação a mais para quem precisa de apoio financeiro revelando sua contribuição para o desenvolvimento humano-acadêmico e social da população discente assistida. Tal apoio permite que o estudante se concentre nos estudos na certeza do suporte para moradia, alimentação, transporte e inclusão digital. Não obstante, apesar de metas tão nobres, era preciso oportunizar que os estudantes explicitassem seus níveis de reconhecimento e satisfação, razão que justifica o presente estudo.

O Quadro 1 mostra a relação entre situação socio econômica e ingresso de estudantes e, a partir do edital do Plano de Permanência do ano de 2020 na Unipampa (Universidade Federal do Pampa, 2020).

Quadro 1. Relação entre situação socio econômica e ingresso de estudantes.

\begin{tabular}{|c|c|}
\hline Renda per capta & Número de estudantes \\
\hline até $\mathrm{R} \$ 500,00$ & 30 \\
\hline até $\mathrm{R} \$ 1000,00$ & 80 \\
\hline até $\mathrm{R} \$ 1650,00$ & 20 \\
\hline $\begin{array}{c}\text { Total de alunos ingressantes no Planode } \\
\text { Permanência em 2020 }\end{array}$ & 130 \\
\hline
\end{tabular}

Fonte: Autores.

Os números acima revelam que a maioria dos estudantes ingressantes nos programas de Assistência Estudantil da Unipampa, possui renda per capita abaixo de um salário mínimo, isto é, com renda familiar não exceder a um salário mínimo e meio por pessoa, como parâmetro de inclusão.

Ressaltamos ainda que o universo do ingresso na universidade é algo extrapola os limites da política e deste artigo, mas 
que devido a problemas como falta de acesso à internet, falta de informação e a falta do limite orçamentário para os editais publicados, muitos alunos ainda ficam à margem dos programas de Assistência Estudantil.

\section{A política de Assistência Estudantil da Unipampa Campus Uruguaiana e caracterização do público-alvo do estudo}

A Pró-Reitoria de Assuntos Estudantis e Comunitários (PRAEC), instância ligada a Reitoria da Unipampa, desenvolve ações de combate à vulnerabilidade socioeconômica como resultado de análises voltadas à redução de seus impactos socioeconômica, no intuito de favorecer a permanência dos estudantes que necessitam de apoio para manter a estabilidade (Universidade Federal do Pampa, 2014) na construção de seu conhecimento científico.

A Unipampa é uma Instituição multicampi, que abrange 10 (dez) cidades do Estado do Rio Grande do Sul. Cada campus também conta com o apoio do Núcleo de Desenvolvimento Educacional (NuDE), que atua também no desenvolvimento de políticas de Assistência Estudantil, resguardando as especificidades de cada campus empenhando-se para adequar-se ao contexto local/regional. O NuDE pertence à Coordenação Acadêmica, oferecendo apoios psicossocial e pedagógico, o que tem contribuído para a constância destes estudantes no ensino superior.

Alguns folhetos são disponibilizados nos murais da Universidade, divulgando informações sobre locadores e imobiliárias locais e, como via de mão dupla, alcançam os estudantes ingressantes, visto que, os custos de hospedagem em hotéis têm custo elevado, ainda que, de forma temporária.

São atribuições multiprofissional do $\mathrm{NuDe}$ (Unipampa, 2015):

a) Atendimento aos estudantes por demanda espontânea ou por indicação docente, o que pode acarretar em encaminhamento à rede socioassistencial do município, orientação de participação em programas de bolsas/auxílios da instituição e/ou programas de apoio pedagógico e psicossocial, etc;

b) Acompanhamento dos estudantes com necessidades educacionais especiais por meio do interface NInA;

c) Avaliação periódica dos beneficiários do Plano de Permanência (nas modalidades acadêmica e socioeconômica) para aferição do atendimento aos critérios para manutenção dos benefícios.

d) Ações de recepção e acolhimento aos estudantes ingressantes.

e) Colaboração com a execução das ações de saúde, cultura, esporte e lazer.

f) Apoio pedagógico aos discentes que solicitarem e assessoria aos docentes do campus na área do desenvolvimento pedagógico educacional, visando à qualidade do trabalho pedagógico de maneira abrangente.

A recepção inicial no NuDE aos estudantes tem gerado conforto e acolhimento principalmente para os residentes em outras cidades os quais encontram-se, muitas vezes, inseguros por não possuírem moradia (acordo de aluguel).

O campus da Unipampa também conta com o Núcleo de Inclusão e Acessibilidade (NINA) por meio do qual o estudante, que necessita de Atendimento Educacional Especializado (AEE), recebe amparo para que goze de todos os direitos estabelecidos para o seu desenvolvimento acadêmico. Uma das ações considerada estratégica é a seleção de monitores que acompanham diretamente estes estudantes auxiliando-os na realização de atividades, deslocamentos, dentre outrasnecessidades que dificultam e limitam a vida acadêmica do público-alvo deste estudo.

Em consonância com a Lei no 13.146 (6/07/2015), voltada a assegurar e promover, em condições de igualdade, o exercício dos direitos e das liberdades fundamentais da pessoa com deficiência, visando à sua inclusão social e cidadania,

[...] a atuação do NINA está voltada para os alunos que apresentam: deficiência na(s) área(s) auditiva, visual, física, intelectual e/ou múltipla; Transtornos Globais de Desenvolvimento - TGD, altas habilidades/superdotação e 
dificuldades específicas de aprendizagem que requeiram Atendimento Educacional Especializado. As ações são desenvolvidas baseando-se nos princípios da colaboração, intersetorialidade e multiprofissionalidade das equipes, alcançando de modo ramificado todas as unidades universitárias (campus) e setores da Reitoria e Pró-Reitorias. (Unipampa, 2014).

A integração do NuDE e do NINA com a PRAEC também encontra identidade com os parâmetros estabelecidos pela Pró-Reitoria de Graduação (PROGRAD). Esta interlocução promove a discussão sob múltiplas perspectivas para “contribuir com a adaptação e a integração no contexto universitário, com a promoção do acesso aos direitos e com o enfrentamento da evasão e da retenção acadêmica” (Universidade Federal do Pampa, 2014).

A regulamentação da Assistência Estudantil da Unipampa, assevera que:

A Assistência Estudantil na Unipampa é regulamentada pela Resolução CONSUNI/UNIPAMPA n. ${ }^{\circ} 84$, de 30 de outubro de 2014, em consonância com o Decreto 7.234, de 19 de julho de 2010, que dispõe sobre o Programa Nacional de Assistência Estudantil (PNAES), e na Portaria Normativa MEC n. 39, de 12 de dezembro de 2007, que institui o Programa Nacional de Assistência Estudantil (PNAES). (Universidade Federal do Pampa, 2014).

Tal regulamentação é essencial para os discentes de graduação do ensino presencial, uma vez que, este fomento, promove a igualdade para os estudantes que necessitam desse amparo para conclusão de seus estudos de nível superior. Estas oportunidades, rumo à democratização do acesso ao conhecimento organizado, desconstroem o lugar historicamente ocupado pelas elites nas Instituições Federais de Ensino Superior (IFES), que contemplam apenas estudantes em condições economicamente estáveis e favoráveis. A realidade regional vivenciada em cada Instituição é contemplada tendo como base de análise, "os critérios de seleção dos estudantes levam em conta o perfil socioeconômico dos alunos, além de critérios estabelecidos de acordo com a realidade de cada instituição” (Brasil, 2019).

O PNAES tem, como objetivo, a oferta de subsídios financeiros (bolsas e auxílios); moradia estudantil e alimentação no Restaurante Universitário (RU) para estudantes em situação de vulnerabilidade socioeconômica que estejam matriculados nos cursos de graduação presencial das IFES, buscando agir preventivamente nas situações de retenção e evasão decorrentes da insuficiência de condições financeiras (Almeida, Oliveira \& Seixas, 2019, p. 192).

Tais diretrizes são assentidas por Dutra \& Santos quando destacam a trajetória história da Assistência Estudantil

(AE):

Em sua trajetória histórica, a AE, a partir dos debates e discussões desenvolvidos pelos diferentes grupos/atores sociais envolvidos em sua construção (estudantes, docentes, gestores, profissionais, Estado), nos diferentes contextos sóciohistóricos em que tem sido abordada, vai adquirindo diversos sentidos e suscitando diferentes posicionamentos quanto a sua implementação. Desse modo, diferentes projetos de assistência ao estudante no espaço universitário têm sido propostos, os quais podem trazer importantes implicações para as formas adotadas para sua operacionalização nas Instituições de Ensino Superior. (Dutra \& Santos, 2017, p. 149).

Vale ressaltar que, quando a opção Institucional é a gestão participativa focada no diálogo intersetorial com os sujeitos da comunidade acadêmica, agrega valores para ambos. Ao contrário, quando a gestão é meritocrática e hierarquizada, limita o desenvolvimento das políticas que enfatizam a Assistência Estudantil (Lago \& Gonçalves, 2019).

Este estudo aposta nas influências que incidem sobre as práticas educativas calcadas na humanização para a participação consciente como elementos essenciais para sustentar a gestão educativa, na busca por evitar que se transformem em mera aplicação técnica de procedimentos e instrumentos administrativos. Por outro lado, “[...] a participação dos atores pedagógicos na gestão escolar tornou-se fundamental, abrindo espaço para o pensar crítico sobre as administrar as práticas educativas” (Barilli, 2020).

Chiavenatto (2003) nos conta que, na década de 20, as teorias das relações humanas se caracterizaram como um movimento humanizador, tanto na educação, quanto nas organizações e os aspectos individuais e sociais, nesta ótica, sobrepujaram os produtivos. Desde lá, apesar de práticas pontuais ainda se assentarem na competição e hierarquização dos postos 
de tomada de decisão, a administração escolar hoje encontra sustentação na gestão participativa na qual a comunidadede aprendizagem (diretores, estudantes, professores, equipes pedagógicas e a família) refletem, discutem e determinam os caminhos para a realização das ações educativas.

Este direcionamento deve sustentar as políticas de Assistência Estudantil a partir da compreensão de a instituição formadora estar cumprindo seu papel social e não realizando favores.

Desta forma, a assistência estudantil já nasce focalizada e residual, destinada aos estudantes pertencentes à classe trabalhadora e, por essa condição, enfrentando, nas suas condições objetivas de vida, dificuldades para a permanência no ensino superior - características herdadas do processo de institucionalização da assistência social como um direito na sociedade brasileira. Ademais, importa destacar que o decreto citado possibilita às IFES instituírem outros critérios de elegibilidade além do recorte de renda per capita já definido, o que na prática se traduz como mais impeditivos de acesso por parte dos/as estudantes e uma maior focalização (Mocelin, 2019, p. 240).

A necessidade de trabalho é alvo de muitos estudantes que buscam o mínimo de estabilidade financeira para estudar, visto que, na modalidade de ensino presencial, os gastos com alimentação e transporte são importantes. Por outro lado, pensar em trabalho é praticamente impossível para o estudante em horário integral, sendo inviável para aqueles conseguem, associar o trabalho e atividades acadêmicas e ainda garantir excelência no rendimento acadêmico (Abrantes, 2012).

No campus Uruguaiana da Unipampa, os cursos de Licenciatura em Ciências da Natureza e Educação Física são noturnos, mas conta como uma parcela importante de discentes que trabalham no período matutino e vespertino. Os demais cursos são diurnos: Medicina, Medicina Veterinária, Aquicultura, Fisioterapia, Enfermagem e Farmácia. Alguns estudantes dos cursos diurnos ainda conseguem trabalhar durante a noite, embora a oferta de trabalho seja difícil.

Alguns estudantes desenvolvem trabalhos autônomos, conseguindo realizar pequenas comercializações (vendas) até mesmo no campus. Alguns reforçam o orçamento por meio de atividades informais (biscates e trabalhos temporários no fim de semana). Outra parcela significativa dos estudantes, conta com o apoio de seus familiares, imprescindível para os provenientes de outras cidades, que deslocaram-se apenas com o objetivo de cursar a graduação.

A graduação, como primeira etapa do ensino superior, deve considerar a realidade da comunidade escolar em que está inserida. O levantamento socioantropológico é um instrumento essencial para averiguar, em caráter quanti-qualitativo, as particularidades dos discentes em seus aspectos de pertencimento, composição familiar e parâmetros socioeconômicos, a fim de conhecer e buscar meios para a adequação de um ensino apropriado às demandas.

Nos amparamos em Carriço et al. (2020), descrevendo que:

Para a elaboração do diagnóstico preliminar da realidade é imprescindível o envolvimento coletivo e cooperativo de grande parte dos sujeitos envolvidos, garantindo, assim, a apreensão mais complexa dos aspectos que envolvem o contexto escolar. [...] além de configurar-se num processo investigativo, também contribui com a formação dos sujeitos envolvidos, que se dá através da busca por referenciais teóricos, na construção coletiva e cooperativa dos instrumentos de produção e análise das informações, especialmente, promovendo práticas educativas dialógicas, através de debates, discussões e reflexões que possam colaborar na construção de novos saberes e na transformação da escola (Franco et al., 2020, 17-18).

A sistematização do levantamento socioantropológico é capaz de sensibilizar o corpo docente, propiciando a implementação de uma educação transformadora e emancipatória. De acordo com Freire (1996, p. 38) “Outro saber de que não posso duvidar um momento sequer na minha prática educativo-crítica é o de que, como experiência especificamente humana, a educação é uma forma de intervenção no mundo", ou seja, as Universidades precisam transformar a região através do conhecimento, e quando as camadas mais vulneráveis são inseridas no Ensino Superior e sua permanência é garantida, estaremos caminhando para a transformação e progresso socioeconômico. 
O surto de coronavírus obrigou que a sociedade entrasse em isolamento social e suspendeu as atividades acadêmicas presenciais previstas para o ano de 2020. Entretanto, a permissão do MEC para o ensino remoto fez com que as universidades se preocupassem com a elevada desigualdade de acesso e com os prejuízos pedagógicos que poderiam surtir. É nesse momento que ações estratégicas de políticas assistencialistas, como o PNAES, podem contribuir com diminuição das consequências desses problemas estruturais (Dib, 2020, p. 15).

O presente estudo, assentido aos pressupostos da educação emancipadora e da gestão escolar participativa ainda procurou sustentação na teoria da antropologia do desenvolvimento que será descrita mais adiante no item metodologia.

\section{Metodologia}

A presente pesquisa possui caráter quanti-qualitativo e natureza exploratória. Optamos por estruturar o protocolo de pesquisa em duas fases - quantitativa e qualitativa. A primeira, refere-se ao levantamento da satisfação geral quanto a política e desafios enfrentados pela população estudada, a partir três categorias principais: saúde mental, equilíbrio financeiro e desafios para adaptação ao ERE traduzidas em cinco questões colocadas no instrumento de coleta de dados. A segunda, tida como perspectiva de continuidade, para contemplar a riqueza das subjetividades dos sujeitos sociais participantes.

Para Gatti (2004),

Os métodos de análise de dados que se traduzem por números podem ser muito úteis na compreensão de diversos problemas educacionais. Mais ainda, a combinação deste tipo de dados com outros oriundos de metodologias qualitativas, podem vir a enriquecer a compreensão de eventos, fatos, processos (p. 13).

Por outro lado, segundo Zanelli (2002), pesquisas qualitativas buscam diagnosticar as particularidades sobre as percepções das pessoas em relação ao mundo/realidade em que vivem, além de, segundo Liebscher (1998), ser um excelente tipo de pesquisa que avalia questões sociais onde os resultados geralmente são de quantificações inviáveis.

Finalmente, a pesquisa exploratória, segundo Gil (2019), "têm como objetivo proporcionar maior familiaridade com o problema, com vistas a tomá-lo mais explícito ou a constituir hipóteses. Pode-se dizer que estas pesquisas têm como objetivo principal o aprimoramento de ideias ou a descoberta de intuições” (p. 26).

A pesquisa é delineada a partir de um estudo de caso, sendo o público-alvo da pesquisa os estudantes regularmente matriculados nos cursos de nível superior da Universidade Federal do Pampa Campus Uruguaiana.

O objetivo da fase quantitativa da pesquisa foi conhecer como os estudantes perceberam os cenários e desafios decorrentes da pandemia em especial levantando as possíveis dificuldades encontrada na articulação com as práticas pedagógicas ligadas ao ensino remoto emergencial (ERE), bem como os níveis de satisfação dos estudantes por meio de suas percepções acerca dos auxílios financeiros disponibilizados pela Universidade para a sua permanência acadêmica.

Para estruturar a pesquisa foram utilizadas as seguintes categorias de análise: saúde mental, equilíbrio financeiro, desafios para adaptação ao ERE traduzidas em cinco questões colocadas no instrumento de coleta de dados.

O instrumento de coleta de dados foi o questionário contendo cinco questões fechadas, foi disponibilizado por meio da ferramenta digital Google Formulários, com acesso on line, enfatizando a participação anônima, voluntária e esclarecida de 101 estudantes bolsistas de Assistência Estudantil da Universidade Federal do Pampa, campus Uruguaiana, que passaram a ser nominados participantes.

A primeira questão buscou compreender os prejuízos à saúde mental dos participantes em função da pandemia. Tal busca se justifica a partir do entendimento de ser a COVID-19 e suas variações, uma das maiores crises mundiais e, sobretudo, caracterizada pela OMS [...] como um dos maiores problemas de saúde pública internacional das últimas décadas, tendo atingido praticamente todo o planeta (World Health Organization, 2020).

Segundo o Ministério da Saúde do Brasil, [...] os cenários e situações trazidos pela pandemia ocasionam perturbações 
psicológicas e sociais que afetam a capacidade de enfrentamento de toda a sociedade, em variados níveis de intensidade e propagação (Ministério da Saúde do Brasil, 2020). Devendo seus sintomas serem caracterizados como não patológicos, esforços emergenciais de diferentes áreas do conhecimento "são demandados para a proposição de formas de lidar com o contexto que permeia a crise" (p. 2).

Ainda cabe salientar quanto à saúde mental, que as sequelas de uma pandemia são maiores do que o número de mortes (Brooks et al., 2020). O distanciamento social, a extinção de postos de trabalho, insegurança alimentar, exclusão e violências impactaram consideravelmente a saúde mental da população. Por ser resultado do somatório de determinantes sociais potencializados pela pandemia, a inclusão da saúde mental como categoria de análise foi considerada importante para este estudo.

No que concerne aos elementos determinantes da saúde mental estudantes de graduação:

[...] estão sujeitos ao sofrimento psíquico por diversos fatores: pessoais, emocionais, pedagógicos, financeiros,políticos e psicossociais, destacando também o isolamento durante a pandemia de COVID-19 e o ensino remoto. Como fatores de proteção ao sofrimento psíquico, os mais apontados nos estudos foram o apoio familiar e a religiosidade. As manifestações clínicas variaram de ansiedade leve a depressão e suicídio (Faria, Silveira \& Viegas, 2021, p. 21).

A segunda questão buscou levantar a percepção dos participantes acerca de como a pandemia refletiu em seu equilíbrio financeiro. Falar sobre "equilíbrio" de renda no Brasil, traz à tona sentidos como a desigualdade, vulnerabilidade e exclusão, chegando à iniquidade como forma desigual mais injusta pois, contra ela, o indivíduo não tem como lutar.

Segundo Barilli e Oliveira (2020), “os determinantes sociais de saúde expressos em fatores políticos, econômicos e sociais da distribuição da saúde e da doença, no interior e entre as sociedades, fazem emergir as vulnerabilidades socioeconômicos, culturais, étnicos/raciais, ambientais e éticas têm sido marcadas por iniquidades sociais, mormente em territórios distantes e periféricos às cidades (Fiorat et al., 2016). Uma pequena parcela das populações mundiais (isoladas no conforto de seus lares), viram emergir das sombras os cenários de pobreza e fome agudizados pela pandemia.

A análise sobre ações de apoio a estudantes certamente não poderia tratar tal tema como subjacente, senão como elemento de fundo articulado com ao conceito de educação emancipadora (Freire, 1987) dos sujeitos sociais e, neste caso, os estudantes que, durante a pandemia, tiveram na universidade, um lócus de apoio de desenvolvimento humano também capaz de contribuir para aplacar este tipo de carência. Desenvolver capacidades cognitivas diante da fome é impossível.

Para Silva e Sousa (2020) “A situação financeira dos discentes e a falta de auxílio estudantil ou bolsa de auxílio social, afeta diretamente o meio pelo qual estes têm acesso à internet, pois esse serviço no Brasil ainda não é gratuito e de qualidade e seu acesso exige uma renda mínima destinada para isso" (p. 300).

Maciel et al. (2016), asseveram que o fator econômico ganhou espaço no debate estudantil e que os suportes tecnológico e físico não podem ser excluídos das políticas de permanência universitária.

A terceira questão presente no instrumento de coleta de dados versou sobre a percepção dos participantes sobre os desafios presentes nos processos adaptação ao ERE que foi uma ação de urgência das instituições educacionais para viabilizar a continuidade dos processos educativos. Seu caráter urgente impingiu a reconstrução de concepções, métodos, estratégias e formas de relacionamento humano relacionando a exiguidade entre apropriação e materialização. Os tempos, formas de ser e fazer próprias da modalidade presencial de ensino deram lugar a outras formas de presencialidade, administração do tempo, articulação entre saberes e construção de conhecimento, enaltecendo o lugar das tecnologias digitais de informação e comunicação. Para isso, porém, os desafios foram muitos, mormente os ligados a infraestrutura de acesso.

Para os estudantes o espaço digital tido como meio de lazer e relacionamentos casuais, transformou-se no único mediador de acesso à educação. A polissemia resultante da apropriação social da nova demanda educacional fez emergir termos que abarcaram desde a modalidade de Educação a Distância (EAD) já legitimada desde o século anterior, passando pela Educação Remota Emergencial (ERE) e, finalmente chegando à Educação Híbrida (EH). Cabe salientar que apesar de taistermos 
estarem sob diferentes entendimentos e intencionalidades, o elemento comum entre elas é o uso das tecnologias para a aprendizagem (Silva \& Souza, 2020).

Logicamente, nos meses de abril de 2019 a aproximadamente março de 2020, marcados pela necessidade de isolamento social, observou-se a intensa discussão em diferentes esferas da sociedade nas quais a ERE foi entendida como saída para manutenção dos processos de ensino-aprendizagem. À época de publicação deste artigo, entretanto, em que a maioria da população brasileira já foi alcançada pela cobertura vacinal (mas ainda sob o risco das novas variantes da doença), já houve o retorno da modalidade presencial de ensino e o termo EH foi consensuado como nova forma de ensinar e aprender para além do período pandêmico. Não obstante, estas colocações situam o período histórico abordado por este estudo, focado afase da ERE.

Behar (2020) define este "novo ensino", referindo-se a "remoto" devido a distância geográfica entre docentes e discentes, enquanto o "emergencial”, por causa das condições em que foi estabelecido, mudando todo o planejamento das práticas de ensino.

Neste período, para além das vulnerabilidades insistentemente colocadas neste escrito, as inseguranças alcançaram as comunidades de aprendizagem dentro e fora da escola. As lacunas de aprendizado expressas em competências básicas (como ler e entender), as carências ligadas à formação de professores para o uso pedagógico de tecnologias digitais (uso de plataformas de ensino, métodos, estratégias e recursos), a inexperiência em aprender digitalmente e a falta de acesso (estrutural, operacional e econômico) saíram das sombras transformando em problemas de todos.

De acordo com Cunha et al. (2021) o ERE foi essencial para a garantia do ano letivo tanto na Educação Básica quanto no Ensino Superior. Entretanto, este intenso processo de adaptações, rendeu aperfeiçoamentos e atualizações dos docentes perante a demanda emergencial no domínio das tecnologias digitais, bem como, o contorno por parte dos alunos na busca de superar a falta de conexão à internet, a carência de equipamentos, sobretudo, o planejamento e gestão do tempo acadêmico em conciliações com interferências familiares.

Neste contexto, a terceira questão objetivou conhecer a realidade dos bolsistas quanto às condições de conexão à internet e equipamentos para acompanhar as etapas síncronas e assíncronas referentes ao ERE de qualidade.

Finalmente, Santos et al. (2021) analisam a importância das Políticas de Assistência Estudantil para a permanência de estudantes do Instituto Federal de Educação, Ciência e Tecnologia do Rio Grande do Norte (IFRN) - Campus Natal Central, durante o ano de 2020 (pandemia). Os relatos das assistentes sociais apontaram que os benefícios não suprem todas as necessidades, porém, contribuem significativamente a permanência dos mesmos no ambiente escolar.

Este estudo serviu como bases para a elaboração a quarta questão na busca por analisar a importância das ações de Assistência Estudantil da Unipampa, segundo a percepção na visão dos participantes.

A quarta questão buscou explicitar a percepção sobre a importância pessoal para a permanência do participante no ensino de nível superior. Tal percepção configura-se como principal feed back para os processos de avaliação e (re)construção das políticas e programas de Assistência Estudantil da Unipampa. Tal busca é então, ratificada pela questão cinco na qual os participantes foram convidados a avaliar a política por meio de seu nível de satisfação dentro de uma escala numérica compreendida entre 1 (insatisfeito) e 5 (muito satisfeito).

\section{Resultados e Ações Desenvolvidas pela Unipampa Campus Uruguaiana}

Para a análise dos dados buscou-se, um arcabouço teórico que se contrapõe à sociologia quatitativista, à etnologia patrimonialista focalizada no informante privilegiado e às sociologia e antropologia ensaísticas, privilegiando o estudo empírico multidimensional dos grupos sociais, através da análise de suas práticas e representações a qual, apesar de não se pretender acabado, propõe uma investigação não-normatizada combinando rigor analítico com um diálogo respeitoso com os grupos que são objeto da intervenção dos dispositivos de desenvolvimento. 
Segundo Carneiro (2012), a socioantropologia do desenvolvimento é uma abordagem intelectual utilizada para a análise de situações (Programas, projetos, ações) de desenvolvimento. "Podemos dizer que essa orientação da socioantropologia do desenvolvimento, de considerar os atores que são objetos da ação de desenvolvimento como capazes, como coprodutores das intervenções de desenvolvimento [...] (Carneiro, 2012, p. 134).

Os dados contemplam tópicos que evidenciam a intensificação da vulnerabilidade socioeconômica consoante aos tempos de pandemia.

Sobre a primeira questão referente à saúde mental frente à pandemia, 86,1\% dos estudantes bolsistas apontaram quea pandemia afetou a sua saúde mental em comparação a 13,9\% que declarou o contrário (Figura 1).

Figura 1 - Percepção dos participantes quanto à sua saúde mental no período da COVID-19.

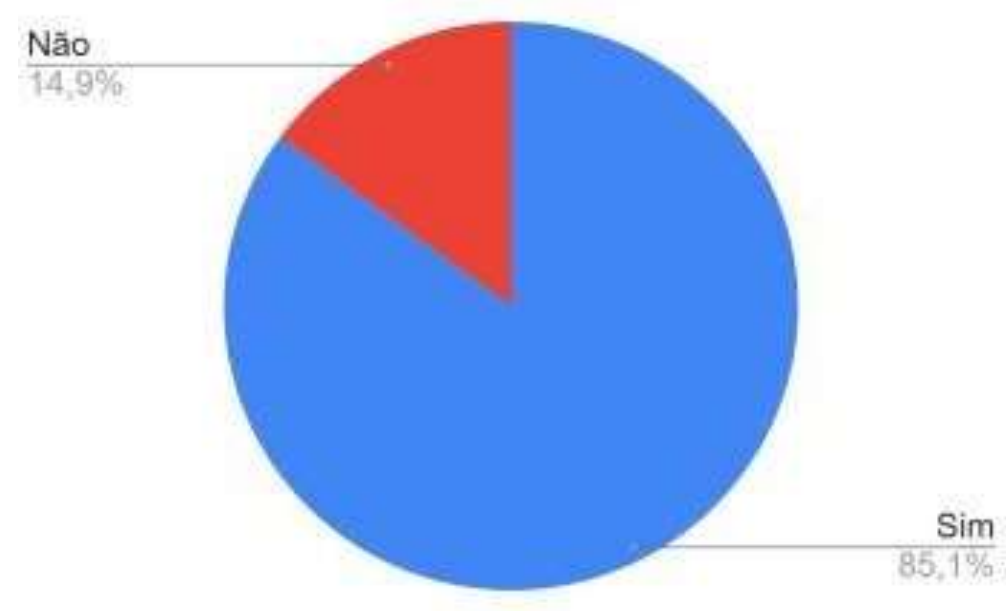

Fonte: Autores.

Referente à segunda questão (categoria equilíbrio financeiro) equilíbrio financeiro, 29,7\% dos participantes declararam ter sofrido desequilíbrios financeiros parcialmente. Apenas 3,0\% declararam não sofrer de problemas financeiro no período de pandemia e 67,3\% declararam ter afetado parcialmente (Figura 2).

De acordo com Coll (2021) em uma publicação institucional da Unicamp, o apoio financeiro através das bolsas "é indispensável para que o aluno em vulnerabilidade socioeconômica se mantenha. Em muitos casos, ele acaba ajudando também no pagamento de contas da família, como água, energia e alimentação. 
Figura 2 - Desiquilíbrio financeiro no período da COVID-19.

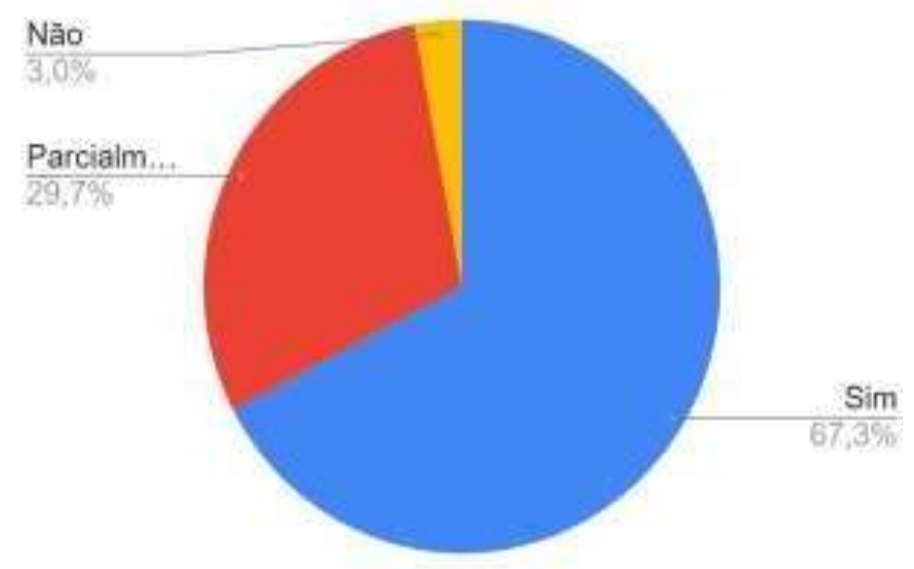

Fonte: Autores.

Concernente à terceira questão, 4,0\% dos estudantes participantes afirmaram não possuírem condições favoráveis (desfavoráveis) de conexão à Internet e equipamentos necessários para o acesso e participação no ERE. Já 37,6\% consideram possuírem condições parcialmente favoráveis de conexão à Internet e equipamentos necessários para o acesso e participação no ERE. Finalmente, 58,4\% dos participantes declararam possuir condições favoráveis de conexão à InterNet e equipamentos necessários para o acesso e participação no ERE em internet e equipamentos (Figura 3).

Figura 3 - Condições de conexão à Internet e equipamentos necessários para o acesso e participação no ERE.

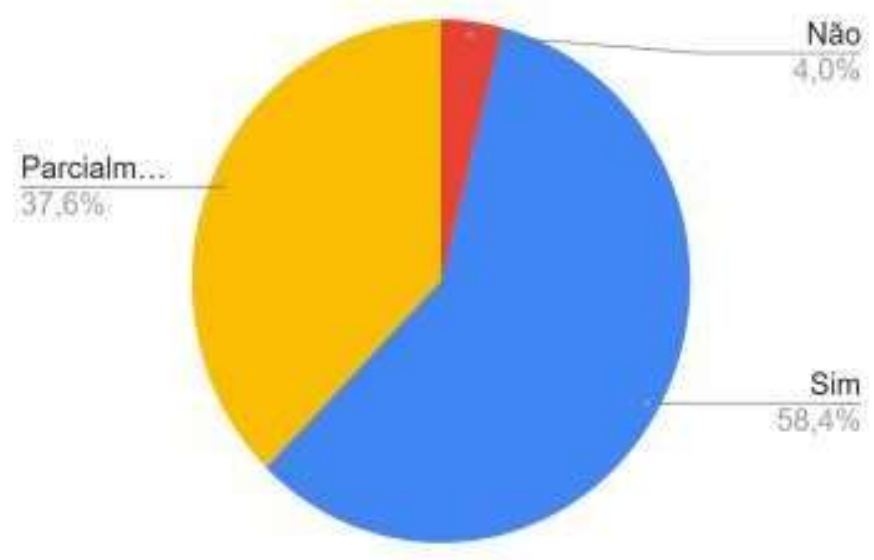

Fonte: Autores.

No que tange à quarta questão, a Figura 4 mostra que 86,1\% dos participantes consideram as ações de Assistência Estudantil como importantes para sua permanência no Ensino Superior. Este achado evidencia a necessidade da promoção de mais ações assistenciais. 6,9\% dos participantes concordam parcialmente que as ações de Assistência Estudantil garantiram a sua permanência no Ensino Superior. Neste sentido, 6,9\% dos estudantes declaram que a Unipampa precisa melhorar no que tange às ações de Assistência Estudantil. 
Figura 4 - Importância das ações e auxílios da Assistência Estudantil da Unipampa foram importantes para sua permanênciano Ensino Superior?

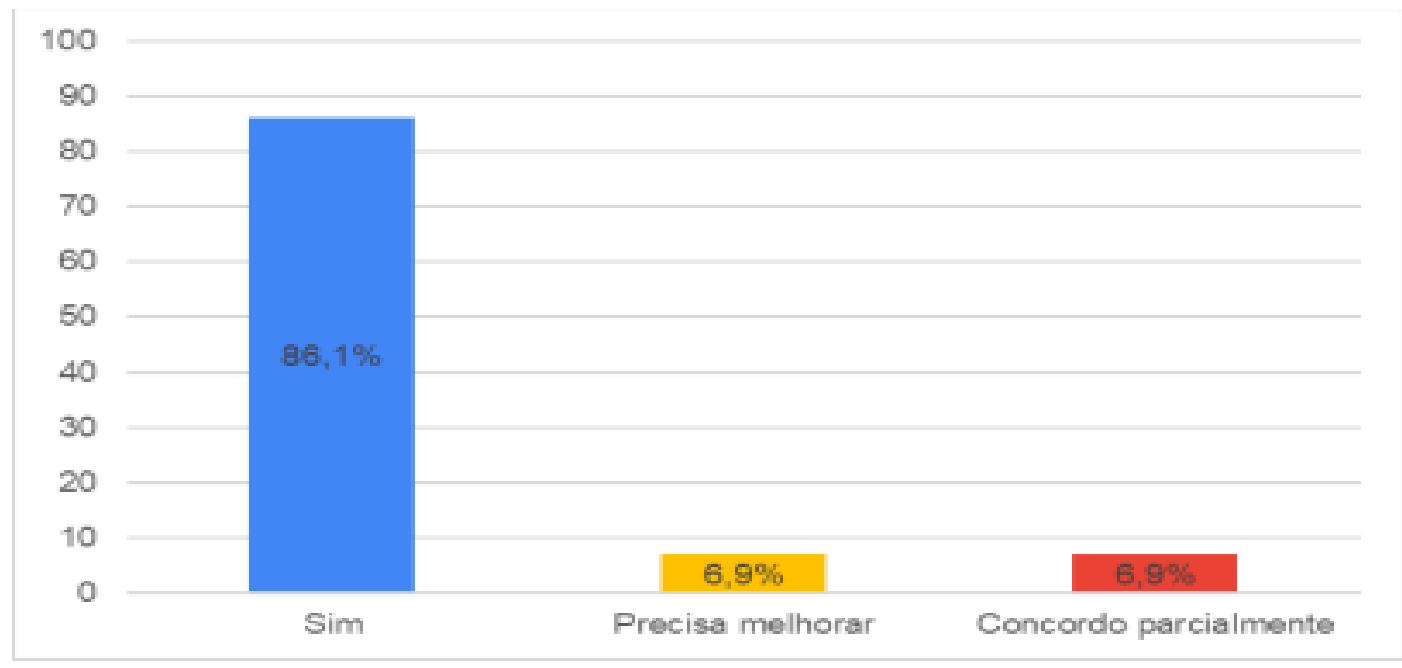

Fonte: Autores.

Culminando o levantamento de percepções dos participantes a quinta questão foi formulada a partir de uma escala de 1 a 5 que contemplando o nível de satisfação dos estudantes frente às Políticas de Assistência Estudantil da Universidade Federal do Pampa - campus Uruguaiana. Assim, a Figura 5 mostra que 43 participantes $(42,6 \%)$ atribuíram nota 5; 44 estudantes $(43,6 \%)$ nota $4 ; 13$ estudantes $(12,9 \%)$ nota $3 ; 1$ estudante $(1 \%)$ nota 2 . Não foram encontrados registros de atribuição de nota 1. Estes resultados inferem a satisfação da maioria dos estudantes, visto que, a maioria atribuiu 4 e 5.

Figura 5 - Nível de satisfação em relação às Políticas de Assistência Estudantil da Unipampa.

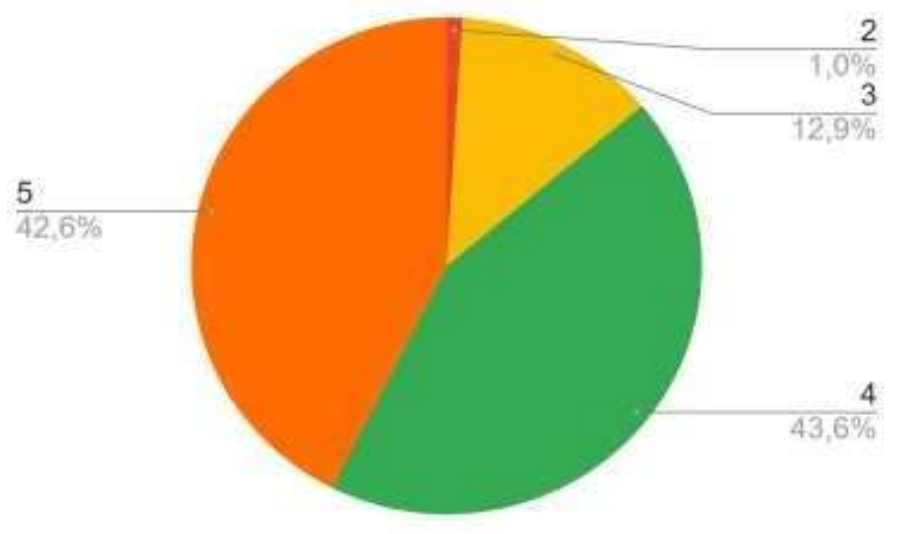

Fonte: Autores.

\subsection{Ações desenvolvidas pela Unipampa Campus Uruguaiana}

As políticas de Assistência Estudantil na Unipampa Campus Uruguaiana, buscaram atenuar os desafios pandêmicos através de um ERE de qualidade. Devido às diretrizes impostas pelo isolamento social muitos estudantes retornaram para suas cidades de origem. Mas, ainda assim, os auxílios foram mantidos, em virtude dos compromissos financeiros assumidos pelos estudantes quanto ao pagamento do aluguel de sua moradia. Novas Políticas de Assistência Estudantil Emergenciais, surgiram para garantir melhor rendimento dos discentes em adaptação ao ERE.

O Quadro 2 sintetiza as estratégias do PNAES. A divisão é constituída em 4 (quatro) blocos, que estipulam linhas 
temáticas para seu desenvolvimento. É importante destacar a importância do acompanhamento de parâmetros de rendimento acadêmico para os alunos contemplados, verificando a assiduidade em frequência e reprovações, garantindo coerência na concessão de auxílios (Silveira, 2012).

Quadro 2. Estruturação da Assistência Estudantil segundo área e linha temática.

\begin{tabular}{|l|ll|}
\hline \multicolumn{1}{|c|}{ Área } & & \multicolumn{1}{c|}{ Linha Temática } \\
\hline Permanência & $\bullet$ & Moradia; \\
& $\bullet$ & Alimentação; \\
& $\bullet$ & Saúde física e mental; \\
& $\bullet$ & Transporte; \\
& $\bullet$ & Creche \\
& $\bullet$ & Condições básicas para atender os portadores de necessidadesespeciais; \\
\hline DesempenhoAcadêmico & $\bullet$ & Bolsas; \\
& $\bullet$ & Estágios remunerados; \\
& $\bullet$ & Ensino de Línguas; \\
& $\bullet$ & Inclusão digital; \\
& $\bullet$ & Fomento à participação político-acadêmica; Acompanhamentopsicopedagógico; \\
\hline Cultura, Lazer eEsporte & $\bullet$ & Acesso à informação e à difusão das manifestações artísticasculturais; \\
& $\bullet$ & Acesso a ações de educação esportiva, recreativa e de lazer; \\
\hline Assuntos daJuventude & $\bullet$ & Orientação profissional sobre mercado de trabalho; \\
& $\bullet$ & Prevenção a atores de risco; \\
& $\bullet$ & Meio ambiente; \\
& $\bullet$ & Política, Ética Cidadania; \\
& $\bullet$ & Saúde, Sexualidade e Dependência química \\
\hline
\end{tabular}

Fonte: Brasil, (2007), adaptado por Silveira, (2012).

Segundo Silveira (2012), a educação é uma política social, que visa garantir os direitos da sociedade, sendo essencial para o exercício da cidadania e emancipação. A autora ainda destaca que "para que se chegue a tanto, há a necessidade que a educação seja democratizada, sendo as ações afirmativas importantes neste processo de garantia de acesso de todos ao espaço educacional" (p. 123). Neste sentido, as Políticas de Assistência Estudantil se caracterizam uma ação afirmativa voltada à garantia da equidade do acesso ao conhecimento de nível superior par e passo ao desenvolvimento das IFES.

Com base na Resolução CONSUNI/UNIPAMPA n 84, de 30 de outubro de 2014 que em seu artigo primeiro define Assistência Estudantil e de acordo com seus princípios, pode-se perceber a influência cultural, social e econômica que a universidade suscita no coletivo estudantil (Universidade Federal do Pampa, 2014). Tal resolução ainda destaca:

Art. $1^{\circ}$ A Assistência Estudantil, por meio de suas ações, visa criar condições para garantir o acesso e a permanência dos estudantes na Instituição, de forma a atender a comunidade universitária multicampi na perspectiva da inclusão social, contribuindo para a construção de uma sociedade mais justa e igualitária.

Art. $2^{\circ}$ As ações dessa política institucional obedecem aos princípios da inclusão social, da isonomia nos processos de seleção, da garantia dos direitos da comunidade discente e da autonomia política nas instâncias consultivas e deliberativas da Universidade.

Partindo destas diretrizes e visando atender as necessidades dos estudantes em termos de acesso e permanência, várias ações são desenvolvidas, como exemplo o Plano de Permanência Estudantil que possibilita aos estudantes, acessar os auxílios financeiros. Na conjuntura atual em que a pandemia impactou diretamente os estudantes, sendo pela suspensão das atividades presenciais ou pela dificuldade de acessar os suportes da universidade, como o restaurante universitário, biblioteca entre outros, a universidade precisou se reinventar-se e implementar estratégias pontuais para amenizar os impactos sociais e financeiros, como a oferta de recursos tecnológicos e cestas básicas com vistas a diminuir os índices de evasão acadêmica.

Frente a insegurança causada pela pandemia, a PRAEC/Unipampa, precisou pensar alternativas de enfrentamento às 
adversidades sociais que foram surgindo. Pelo fato de o semestre letivo já ter iniciado, muitos estudantes já tinham se deslocado dos seus estados de origem para a cidade do campus e, portanto, sem condições financeiras que viabilizassem o retorno às suas casas.

Diante desta realidade e sem a perspectiva de retorno presencial das atividades acadêmicas, foram publicados editais de Apoio Emergencial COVID-19 para ingressantes do primeiro semestre dos cursos de graduação, com renda per capita não excedente a um salário mínimo e meio e que residissem em outros municípios.

Para os estudantes vindos de outros estados, foi destinado uma parcela única no valor de $\mathrm{R} \$ 600,00$ para que pudessem retornar às suas casas. Já aqueles que moravam em outros municípios do estado do Rio Grande do Sul, receberam uma parcela única no valor de $\mathrm{R} \$ 300,00$, além de ajuda para deslocamento com o micro-ônibus da Instituição para o retorno aos locais de origem.

O Apoio Emergencial COVID-19 para não ingressantes (Edital 78/2020), foi direcionado aos estudantes de graduação que permaneceram na cidade sede do campus no período da pandemia e que já estavam há algum tempo cursando a graduação. Para eles foi ofertado os auxílios moradia de R \$250,00 e alimentação de R \$200,00, por um período de 5 (cinco) meses.

A fim de fomentar a inclusão digital, a UNIPAMPA, publicou o Edital de $n^{\circ} 136 / 2021$, o qual, buscou levantar informações sobre estudantes que estivessem precisando dos recursos tecnológicos adequados para dar prosseguimento dos estudos.

Para os estudantes em situação de vulnerabilidade socioeconômica e também ingressantes por cotas, houve um comodato de celulares e quites de apoio às atividades de ERE - AERES, todas visando o acesso democrático às atividades acadêmicas síncronas e assíncronas, primordialmente durante o período de pandemia. O referido edital atendeu ao todo 43 estudantes da Instituição distribuídos entre os 10 campi. O campus Uruguaiana atendeu 7 estudantes.

Outra medida adotada no intuito de minimizar as desigualdades foi o levantamento realizado por $e$-mail sobre o interesse dos alunos em receber cestas básicas, resultando em 95 solicitações. Foram entregues 56 cestas no mês de agosto/2021. Porém, como nem todos foram contemplados, foi preciso proporcionar um auxílio alimentação complementar emergencial, através do

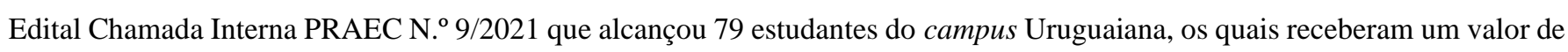
$\mathrm{R} \$ 250,00$, especificamente para aqueles estudantes que se encontram na cidade sede do campus, no período de suspensão das atividades presenciais.

\subsection{Recursos oferecidos aos discentes}

Regularmente a Unipampa conta com o um edital de Apoio ao Ingressante, exclusivamente para alunos vindos de outras cidades/estados. Este edital visa garantir que questões como moradia e alimentação deste estudante sejam contempladasaté seu ingresso no Programa de Permanência, programa que move a Assistência Estudantil na Unipampa. Em suma, o apoio Emergencial tem caráter provisório e dura cerca de quatro meses. Excepcionalmente, a partir do ano de 2020, em função da pandemia do coronavírus, este edital não foi publicado.

O Plano de Permanência, principal ação da Assistência Estudantil da Unipampa, conta com os auxílios alimentação, moradia, transporte, inclusão digital e auxílio creche, voltado a alunos em situação de vulnerabilidade socioeconômica, cuja as famílias não tenham renda per capita excedente a um salário mínimo e meio. É viabilizado através de um edital anual, onde ingressam cerca de 130 a 160 alunos e estes podem permanecer no programa até a conclusão de seu curso, desde que permaneçam dentro dos critérios de inclusão.

Critérios que visam um aproveitamento maior, como não ter reprovação por frequência no semestre anterior, ter no mínimo $60 \%$ de aproveitamento nas disciplinas no semestre anterior e estar matriculado em, no mínimo, 20 créditos semanais, no ERE foram reduzidos para $25 \%$ de aproveitamento das disciplinas no semestre anterior e estar matriculado em no mínimo 8 
créditos semanais.

Para o estudante que não atingiu esses critérios no quesito aproveitamento, ainda existiu a possibilidade de encaminhamento ao apoio pedagógico, previsto no Plano Nacional de Assistência Estudantil, em que o estudante comdificuldade de aprendizagem é acompanhado por um profissional da área pedagógica, onde são trabalhadas questões de ensino, dificuldade de concentração, métodos de memorização entre outros.

Para os ingressantes quilombolas e indígenas são publicados editais específicos tanto para ingresso e permanência por meio de atividades de ensino, pesquisa, extensão e aquelas de viés social e cultural, a fim de atender as demandas dessas comunidades, como para seleção de monitores no intuito de auxiliá-los em suas dificuldades no âmbito universitário.

Como exemplo podemos citar o edital da Chamada Interna PRAEC N 5/2019, que objetivou complementar a política de apoio aos discentes indígenas e quilombolas, ingressantes por meio de processo seletivo específico, ou através da reserva de vagas pelo Sistema de Seleção Unificada (Sisu) para indígenas e quilombolas, no ano letivo de 2019, traz em seu item 2 Finalidade:

I - estimular o conhecimento e fomentar discussões sobre a cultura indígena e quilombola no ambiente acadêmico; II - oportunizar a inserção dos discentes indígenas e quilombolas nos diversos espaços da Universidade. (Unipampa, 2019, p. 1).

Tais atributos revelam o quão importante são as ações desenvolvidas na Unipampa para acolher, e incentivar estes grupos de indivíduos em suas dificuldades de adaptação e permanência em uma realidade dispare do que estão acostumados a vivenciar.

\section{Considerações Finais}

As ações de Assistência Estudantil previstas no PNAES contribuem para a permanência dos estudantes no ensino de nível superior e redução da a evasão por meio da oferta de apoio humano e sócio financeiro. Aliado a isso, a integração e articulação interinstitucional se explicita no diálogo com os estudantes, estabelecendo uma comunicação de mão-dupla ao mesmo tempo em que retro alimenta o planejamento, avaliação e reconstrução de ações integradas.

Frente aos contextos trazidos pela pandemia, a Unipampa, por meio de sua pró-reitora de assuntos estudantis e comunitários, empenhou-se na busca por alternativas de enfrentamento das dificuldades vivenciada por seus estudantes, desde viabilizar o acesso às aulas remotas, passando pelo combate da fome pela entrega de cestas básicas, até as que buscaram a garantia dos direitos por meio dos editais de repasse de renda.

No intuito de incentivar os estudantes indígenas e quilombolas no desenvolvimento acadêmico, foi publicada a Chamada Interna ${ }^{\circ}$ 08/2021 referente ao auxílio de desenvolvimento acadêmico indígena e quilombola - ADAIQ, com a finalidade de:

Promover a iniciação na vida acadêmica dos alunos indígenas e quilombolas, por meio de atividades nas modalidades ensino, pesquisa, extensão e ações sociais, culturais e de atenção à diversidade no âmbito da comunidade acadêmica, que proporcionem a ligação entre o curso e as demandas das comunidades indígenas e quilombolas, incluindo seus saberes e sua cultura, na perspectiva da interculturalidade, bem como: a) estimular o conhecimento e fomentar discussões sobre a cultura indígena e quilombola no ambiente acadêmico; b) oportunizar a inserção dos discentes indígenas e quilombolas nos diversos espaços da Universidade (Universidade Federal do Pampa, 2021, p. 1).

Em decorrência deste edital foi proporcionado a estes estudantes um auxílio no valor de $\mathrm{R}$ \$240,00 mensais, que atenuou os entraves enfrentados pelos mesmos no período de atividades remotas.

Ressalta-se que a Unipampa, através de seu corpo docente e técnico atua em prol de todos os estudantes articulando diversas ações para o atendimento das demandas em geral e aquelas específicas para os mais vulneráveis, como os programas e auxílios implantados. 
O ideário institucional é que sejam atendidos um maior número de beneficiários possíveis, pois só assim os estudantes terão oportunidades equânimes no acesso e permanência na Instituição. É fato que mesmo com os esforços institucionais, a conjuntura política vigente no país incide nas ações da universidade, expressas nos cortes orçamentários quejá estavam vigorando, agravados pela crise econômica e social trazidas pela pandemia.

O Quadro 3 exemplifica alguns destes auxílios oferecidos pela Unipampa como base em documentos da instituição:

Quadro 3. Benefícios socioeconômicos que são disponibilizados aos alunos.

\begin{tabular}{|c|c|c|}
\hline \begin{tabular}{|c|} 
Programa/auxílio \\
\end{tabular} & Requisitos & Valor \\
\hline $\begin{array}{l}\text { Auxílio - Alimentação } \\
\text {-visa contribuir com as despesas emtorno da } \\
\text { alimentação (refeição) dos estudantes }\end{array}$ & $\begin{array}{l}\text { - Não exceder o máximo de renda per capita. } \\
\text { - Mínimo } 8 \text { créditos no remoto e } 20 \text { créditos no presencial } \\
\text { - Entrega de documentação comprobatória de situação } \\
\text { socioeconômica e demaiscritérios estabelecidos em edital }\end{array}$ & $\mathrm{R} \$ 200,00$ \\
\hline $\begin{array}{l}\text { Auxílio - Transporte } \\
\text {-visa contribuir com despesa de }\end{array}$ & $\begin{array}{l}\text { - Não exceder o máximo de renda per capita } \\
\text { - Mínimo } 8 \text { créditos no remoto e } 20 \text { créditos }\end{array}$ & $\mathrm{R} \$ 80,00$ \\
\hline $\begin{array}{l}\text { transporte até o campus e/ou para a realização } \\
\text { de atividade acadêmicas regulares }\end{array}$ & $\begin{array}{l}\text { no presencial } \\
\text { - Entrega de documentação comprobatóriade situação } \\
\text { socioeconômica e demaiscritérios estabelecidos em edital }\end{array}$ & \\
\hline \begin{tabular}{l}
\multicolumn{4}{|c|}{ Auxílio - Transporte Rural } \\
-visa contribuir com as despesas com \\
transporte na realização de atividades \\
acadêmicas para os que comprovem residir na \\
zona rural do município-sede do campus
\end{tabular} & $\begin{array}{l}\text { - Não exceder o máximo de renda per capita } \\
\text { - Mínimo } 8 \text { créditos no remoto e } 20 \text { créditos no presencial } \\
\text { - Entrega de documentação comprobatória de situação } \\
\text { socioeconômica e demaiscritérios estabelecidos em edital }\end{array}$ & $\mathrm{R} \$ 100,00$ \\
\hline \begin{tabular}{l}
\multicolumn{1}{|c|}{ Auxílio - Moradia } \\
-visa contribuir com as despesas decorrentes de \\
pagamento de aluguel ou similar
\end{tabular} & $\begin{array}{l}\text { - Não exceder o máximo de renda per capita } \\
\text { - Mínimo } 8 \text { créditos no remoto e } 20 \text { créditos no presencial } \\
\text { - Entrega de documentação comprobatória de situação } \\
\text { socioeconômica demais critériosestabelecidos em edital }\end{array}$ & $\mathrm{R} \$ 250,00$ \\
\hline $\begin{array}{l}\text { Auxílio - Creche } \\
\text {-para auxiliar os estudantes quetenham filhos } \\
\text { em idade escolar de 0 a } 5 \text { anos }\end{array}$ & $\begin{array}{l}\text { - Não exceder o máximo de renda per capita } \\
\text { - Mínimo } 8 \text { créditos no remoto e } 20 \text { créditos no presencial } \\
\text { - Entrega de documentação comprobatória de situação } \\
\text { socioeconômica e demaiscritérios estabelecidos em edital }\end{array}$ & $\mathrm{R} \$ 80,00$ \\
\hline \begin{tabular}{l}
\multicolumn{4}{c|}{ Auxílio - Inclusão digital } \\
-Caráter provisório $\quad$ (no ensino \\
remoto) \\
-Visa auxiliar alunos com gastoscom internet
\end{tabular} & $\begin{array}{l}\text { - Não exceder o máximo de renda per capita } \\
\text { - Mínimo } 8 \text { créditos no remoto e } 20 \text { créditos no presencial } \\
\text { - Entrega de documentação comprobatória de situação } \\
\text { socioeconômica e demaiscritérios estabelecidos em edital }\end{array}$ & $\mathrm{R} \$ 95,00$ \\
\hline
\end{tabular}

Fonte: Adaptado da Universidade Federal do Pampa (2014).

As três categorias de análise propostas pelo presente trabalho revelaram limitações importantes à permanência dos estudantes, mas, segundo à sua percepção encontra base de resistência e enfrentamento nas políticas de Assistência Estudantilda Unipampa.

Atualmente, vivemos o sucateamento das Universidades públicas, devido a falta de recursos financeiros e as políticas de repasse de renda vem sendo cada vez mais afetadas. Neste cenário, a Política de Assistência Estudantil, tem sido a ação que vem garantindo condições dignas de permanência para o estudante reforçando a necessidade de apoio do Estado para a sua manutenção consolidação por meio do incremento do acesso para quem precisa.

As perspectivas para a continuidade da pesquisa recaem sobre a realização da fase qualitativa bem como sobre a investigação da relação entre as políticas de Assistência Estudantil e o rendimento acadêmico-universitário.

\section{Referências}

Abrantes, N. N. F. (2012). Trabalho e estudo: uma conciliação desafiante. Anais do IV FIPED, Campina Grande: Realize Editora, Brasil. https://www.editorarealize.com.br/artigo/visualizar/485.

Almeida, M. R., Oliveira, I. F., \& Seixas, P. S. (2019). Programa Nacional de Assistência Estudantil em uma universidade pública. Psicologia em Pesquisa, 13(2), 191-209. https://dx.doi.org/10.34019/1982-1247.2019.v13.25910.

Appenzeller, S., Menezes, F. H., Santos, G. G., Padilha, R. F., Graça, H. S., \& Bragança, J. S. (2020). Novos Tempos, Novos Desafios: Estratégias para 
Equidade de Acesso ao Ensino Remoto Emergencial. Revista Brasileira de Educação Médica, 44(Sup.1), e0155. https://doi.org/10.1590/1981-

5271v44.supl.1-20200420.

Barilli, E. C. (2020). Aprendizagem ativa e metodologias ativas, de onde vêm: lima abordagem teórico-prática. In: Martins, G. (Org.). Metodologias Ativas: métodos e práticas para o século XXI. Quirinópolis: Editora IGM.

Barilli, E.C., \& Oliveira, R. M. (2020). Educação a distância, tecnologia e ensino da saúde na esfera pública: uma experiência na formação de professores da educação básica. In: Silva, D., \& Jorge, W. J. (Ogrs). Educação a distância: novas possibilidades e desafios para o ensino. Maringá: Uniedusul, Cap. 21. pp. 206-220.

Brasil. Constituição (1988). Constituição da República Federativa do Brasil. Brasília, DF: Senado Federal.

Brooks, S. K., Webster, R. K., Smith, L. E., Woodland, L., Wessely, S., Greenberg, N., \& Rubin, G. J. (2020). The psychological impact of quarantine and how to reduce it: rapid review of the evidence. The Lancet, 395(102227), 912-920. https://doi.org/10.1016/S0140-6736(20)30460-8.

Brasil (2007). Fórum Nacional de Pró-reitores de Assuntos Estudantis e Comunitários. Plano Nacional de Assistência Estudantil. http://www.fonaprace.andifes.org.br/site/wp-content/uploads/2016/05/fc3b3rum-nacional-dos-prc3b3-reitores-de-assuntos-estudantis-e-comunitc3a1rios-20anos3.pdf.

Brasil (2010). Decreto n 7.234, de 19 de julho de 2010. Dispõe sobre o Programa Nacional de Assistência Estudantil - PNAES. Lex: Presidência daRepública Casa Civil Subchefia para Assuntos Jurídicos, Brasília, DF.http://www.planalto.gov.br/ccivil03/ato2007-2010/2010/decreto/d7234.htm.

Brasil (2019). Ministério da Educação. Plano Nacional de Assistência Estudantil - PNAES. Recuperado em Ago 29, 2021 de http://portal.mec.gov.br/pnaes.

Castioni, R., Melo, A. A. S., Nascimento, P. M., \& Ramos, D. L. (2021) Universidades federais na pandemia da Covid-19: acesso discente à internet e ensino remoto emergencial. In Memorian: Dedicamos este texto à nossa co-autora, Daniela Lima Ramos, falecida durante o processo da presente publicação. Ensaio: Avaliação e Políticas Públicas em Educação, 29(111), 399-419. https://doi.org/10.1590/S0104-40362021002903108.

Carneiro, M. S. (2012). Práticas, discursos e arenas: notas sobre a socioantropologia do desenvolvimento. Sociologia e Antropologia, 2(4), 129-158. https://doi.org/10.1590/2238-38752012v247.

Chiavenato, I. (2003). Introdução à teoria geral da administração: uma visão abrangente da moderna administração das organizações. (7a. ed.). Elsevier.

Coll, L. (2021). O desafio da permanência estudantil durante a pandemia. Atualidades - Unicampi. https://www.unicamp.br/unicamp/noticias/2021/07/02/odesafio-da-permanencia-estudantil-durante-pandemia.

Cunha, F. I. J., Mourad, L. A. F. A. P., \& Jorge, W. J. (2021).Ensino Remoto Emergencial: Experiência de Docentes na Pandemia. Uniedusul

Dib. A. M. (2020). A Relevância do Programa Nacional de Assistência Estudantil na Educação. In Silva, A. J. N., \& Bonfim, A. L. (Orgs). Militância políticae teórico-científica da educação no Brasil. Atena.

Dutra, N. G. R., \& Santos, M. F. S. (2017). Assistência estudantil sob múltiplos olhares: a disputa de concepções. Ensaio: Avaliação e Políticas Públicas em Educação, 25(94), 148-181. https://doi.org/10.1590/S0104-40362017000100006.

Faria, E. L., Silveira, E. A. A., \& Viegas, S. M. F. (2021). Vivências cotidianas na graduação e o impacto na saúde mental de estudantes: scoping review. SciELO Preprint. https://doi.org/10.1590/SciELOPreprints. 2744.

Fiorati, R. C., Arcêncio, R. A., \& Souza, L. B. (2016). As iniquidades sociais e o acesso à saúde: desafios para a sociedade, desafios para a enfermagem Rev. Latino-Am. Enfermagem. 24:e2683. http://dx.doi.org/10.1590/1518-8345.0945.2687.

Franco, R. M., Carriço, M. R. S., Galarça, R. C. G., \& Silva, F. F. da. (2020). Socio-anthropological research: dialogical strategy for the construction of the preliminary diagnosis of school reality. Research, Society and Development, 9(7), e514974330. https://doi.org/10.33448/rsd-v9i7.4330.

Freire, P. (1996). Pedagogia da autonomia: saberes necessários à prática educativa. Paz e Terra.

Gatti, L. B. (2004). Estudos quantitativos em educação. $\quad$ Educação $\quad e \quad P e s q u i s a, \quad 30(1)$ 11-30, https://www.scielo.br/j/ep/a/XBpXkMkBSsbBCrCLWjzyWyB/?format=pdf\&lang=pt

Lago, T. M., \& Gonçalves, L. M. (2019). Gestão das Políticas de Assistência Estudantil: Possibilidades para Permanência no Ensino Superior. Gestão e Planejamento, 20, 512-527. https://doi.org/10.21714/2178-8030gep.v20.5806.

Maciel, C. E., Lima, E. G. dos S., \& Gimenez, F. V. (2016). Políticas e Permanência para Estudantes na Educação Superior. Políticas e permanência para estudantes na educação superior. Revista Brasileira de Política e Administração da Educação-Periódico científico editado pela ANPAE, 32(3), 759-781. https://doi.org/10.21573/vol32n32016.68574.

Ministério da Saúde (Brasil). (2020). Saúde mental e atenção psicossocial na COVID-19: um guia para gestores. Fiocruz. Recuperado em Dez 19, 2021 de http://www.fiocruzbrasilia.fiocruz.br/wp-content/uploads/2020/04/Sa\%c3\%bade-Mental-e-Aten\%c3\%a7\%c3\%a3o-Psicossocial-na-Pandemia-Covid-19recomenda\%c3\%a7\%c3\%b5es-para-gestores.pdf.

Mocelin, C. E. (2019). Assistência estudantil como política de proteção social: uma possibilidade de seguridade social ampliada e intersetorial. O Social em Questão, (45), 239-260. Recuperado em Dez 19, 2021 de http://osocialemquestao.ser.puc-rio.br/media/OSQ_45_art_11.pdf.

Pina, I. L., \& Rosa, F. L. B. (2018). Assistência Estudantil na Universidade Federal do Pampa - Unipampa. Anais do 10 Salão de Ensino, Pesquisa eExtensão - SIEPE, Santana do Livramento, RS, Brasil. https://guri.unipampa.edu.br/uploads/evt/arq_trabalhos/17839/seer_17839.pdf. 
Research, Society and Development, v. 11, n. 1, e34911124707, 2022

(CC BY 4.0) | ISSN 2525-3409 | DOI: http://dx.doi.org/10.33448/rsd-v11i1.24707

Santos, S. R. dos., Drago, C. C., Azevedo, M. A. de., \& Ferreira, M. A. dos S. (2021). Políticas de assistência estudantil e permanência de estudantes napandemia: . Revista Labor, 1(26), 167-192. https://doi.org/10.29148/labor.v1i26.71948.

Silveira. M. M. (2012). A Assistência Estudantil no Ensino Superior: uma análise sobre as políticas de permanência das universidades federais brasileiras. Dissertação, Mestrado em Política Social, Universidade Católica de Pelotas, Pelotas-RS, Brasil.

Universidade Federal do Pampa (2014). Assistência Estudantil. https://sites.unipampa.edu.br/sisu/assistencia/.

Universidade Federal do Pampa (2014). Resolução No 84, 30 de Outubro de 2014. https://sites.unipampa.edu.br/consuni/files/2010/06/res-_84_2014-politicade-assistencia-estudantilb.pdf.

Universidade Federal do Pampa (2019). Chamada Interna PRAEC n 5/2019. Inscrição de Candidatos ao Auxílio de Desenvolvimento Acadêmico Indígena e Quilombola (2a ed). https://sites.unipampa.edu.br/praec/files/2019/06/01_chamada-interna-praec-5-2019.pdf.

Universidade Federal do Pampa (2020). Edital n ${ }^{\circ}$ 25/2020. Inscrição e Seleção de Candidatos ao Plano de Permanência. https://unipampa.edu.br/portal/sites/default/files/documentos/edital_0252020_edital_de_inscricao_e_selecao_de_candidatos_ao_plano_de_permanenc ia.pdf.

Universidade Federal do Pampa (2021). Chamada Interna PRAEC n 8/2021. Inscrição de Candidatos ao Auxílio de Desenvolvimento Acadêmico Indígena e Quilombola. https://sites.unipampa.edu.br/praec/files/2021/08/chamada-interna-no-8_2021.pdf.

Universidade Federal do Pampa (2021). Edital N 136/2021 - Edital de Manifestação de Interesse para Destinação, através de Comodato, de celulares e Kits de Apoio às Atividades de Ensino Remoto Emergenciais (AERES) para estudantes em Vulnerabilidade Socioeconômica e/ou Ingressantes por cotas. https://unipampa.edu.br/portal/edital-1362021-edital-de-manifestacao-de-interesse-para-destinacao-atraves-de-comodato-de-celulares.

Universidade Federal do Pampa. (2014). Núcleo de Inclusão e Acessibilidade. https://sites.unipampa.edu.br/nina/apresentacao/sobre-o-nina/.

Universidade Federal do Pampa. (2015). Núcleo de Desenvolvimento Educacional. https://unipampa.edu.br/uruguaiana/nude.

World Health Organization. (2020). Coronavirus disease 2019 (COVID-19): situation report - $78 . \quad$ https://www.who.int/docs/defaultsource/coronaviruse/situation-reports/20200407-sitrep-78-covid-19.pdf?sfvrsn=bc43e1b_2.

Zanelli, J. C. (2002). Pesquisa qualitativa em estudos da gestão de pessoas. Estudos de Psicologia, 7(esp.), 79-88. https://doi.org/10.1590/S1413$294 X 2002000300009$

Liebscher, P. (1998). Quantidade com qualidade? Ensino de métodos quantitativos e qualitativos em um programa de mestrado em LIS. Library Trends,46(4), 668-680. https://www.ideals.illinois.edu/bitstream/handle/2142/8180/librarytrendsv46i4f_opt.pdf.

Gil, A. C. (2019). Métodos e técnicas de pesquisa social (7a. ed.). Atlas. 